\title{
IMPROVING EARTHQUAKE PERFORMANCE OF REINFORCED CONCRETE FRAMES WITH CFRP
}

\author{
Ertan SÜLEV, Fatih ALTUN
}

\begin{abstract}
Better understanding reinforced concrete behaviour greatly enhances ones grasp of design essentials and helps to improve them further. Therefore, especially laboratory research activities play an important role in designing earthquake resistant structures and retrofitting existing ones. Through experimental research activities fundamental principles can be put forward to prevent structures undergoing excessive damage during earthquakes. In this study it is aimed to present to seismic behaviour of a one-storey and one span reinforced concrete frame retrofitted by CFRP wrapping. Displacement controlled loading is applied and hysteretic curve of the system is obtained. The corresponding backbone curve is drawn and results are discussed in terms of strength and ductility. By identifying crack development in terms of crack locations and intensity it is aimed to track changes in system behaviour. With hysteretic curve has been demonstrated energy consumption. As a result of experimental data and analytical solution, force-displacement curve is defined and the reason of the change of behaviour is defined with the splitting of the cracks after peak displacements. The reason of the behaviour difference in non-linear region is judged as the splitting of the cracks reduces system stiffness. Then frame system columnbeam joint point and column-foundation joint point are defined as plastic hinge with $0.34 \mathrm{~mm}$ thickness of two axis reinforced with single-layer wrapping with impregnated in epoxy resin multi-directional fabrics. After the retrofit, the behaviour of the specimen under the effect of cycle loads done are investigated. As a result, fiber reinforced frames improvement is focused on ductility rather than strength. So it can be concluded that fiber reinforcement should be used in restoring structural elements into their pre-damaged capacity but not as a strengthening measure.
\end{abstract}

Keywords-cfrp, frame system, retrofit, strengthening, reinforcement, strength, ductility

\section{Introduction}

Reinforced concrete structures in our country generally lack sufficient lateral strength and ductility. It is likely to expect a weak seismic behaviour with such poorly constructed structures. Therefore, it is essential to identify possible failure modes and weak links in order to avoid them and increase the earthquake safety of existing building stock. Important contributions to this subject both on element based and system based can be readily found in literature.

Ertan SÜLEV/Research Assistant

Fac. Of Eng., Dep. Of Civil Engineering, Nuh Naci Yazgan University

Turkey

Fatih ALTUN/Prof.

Fac. Of Eng., Dep. Of Civil Engineering, Erciyes University Turkey
Element-based researches mainly focused on reinforced concrete beams, columns and structural walls. Ozgur. A. studied to presented test results on strengthening of shear deficient RC beams by external bonding of carbon fiber reinforced polymer (CFRP) straps. Reinforcement concrete beams with a $\mathrm{T}$-section were tested under cyclic loading in the experimental program. The test results confirmed that all CFRP arrangements improved the strength, stiffness and energy dissipation capacity of the specimens significantly [1]. Yalcin $\mathrm{C}$ et al. studied on the retrofitting of reinforced concrete columns using carbon fiber reinforced polymer (CFRP) sheets to improve their strength and ductility capacities. Plain rebars, inadequate splicing lengths and insufficient stirrup spacing were the main parameters to reflect the old construction practice [2].V.Singh, et al. in the studied, the effect on the strength of beam-column joints initially stressed to three different stress levels, retrofitted with CFRP jackets has been presented. CFRP strengthening has been carried out for beam-column joints already stressed to three different stress levels. The jackets have been provided in L-shape and at $45^{\circ}$ orientation to the joint in two layers. The results show improvement in the ultimate load carrying capacity $(7-12 \%)$ of the retrofitted beams, when compared to the control beams along with an increase of $15 \%$ in yield load for each of such exterior beam- column joints. It showed that there was an increase of $17.36 \%$ and $26.94 \%$, respectively, in the stiffness until the first time the crack was seen.[3]. Reyes Garcia, et all tested the first specimen is control frame and examined the behaviour under cyclic lateral loading without any strengthening. Firstly, the other specimen was cyclic lateral load and after strengthening with CFRP after cracks and damage occurred, the new condition was observed and analytical modelling was done. As a result, the CFRP specimen is showed $65 \%$ less damage than the first test model. [4]. Ritchie et al. tested inadequately fitted beams to see how externally bonded CFRP sheets strengthening using FRP in their study is functional. The fibers made of glass, carbon and aramid fibers are bonded to the pull face of the beams using epoxy. FRP has been preferred for this application due to its properties such as good tensile strength, lightness and corrosion resistance. FRP has developed an analytical method to calculate the maximum strength and rigidity of the reinforced beam with bending. As a result of FRP reinforced beams increased in service load, stiffness $17 \%$ - 99\%, bearing strength $47-97 \%$. They reported an acceptable match with analytically calculated and experimentally obtained load-displacement curves. Most beams did not fail at the maximum moment region during tests. The limit loads are applied to the beams and ultimate strength at the maximum moment region is showed a maximum difference of 5\% with the calculated values.[5]. Geng, Z.J et. al conducted the research effort in improving the ductility of concrete column-to-beam connection and the capability of 
connections containing insufficient development length. CFRP tow sheets were wrapped around the column near the joint region for ductility retrofitting, and were longitudinally bonded to and/or wrapped around the column near the joint with a set of steel angles and rods for development retrofitting. Repeated loading-unloading-reloading were applied on ductility specimens for simulating seismic loads. Development specimens were tested under monotonic loading. A total of 19 concrete column-to-beam connection specimens were tested. Ductility retrofitting has resulted in significant improvement in ductility and 24-35\% increase in ultimate loading capacity. The development retrofitting has demonstrated $154-172 \%$ increase in ultimate loading capacity.[6].

In this study, a single-story plane frame has been produced with a scale of $1 / 2$. This frame is cyclically displaced up to 0.01 drift level corresponding to minimum damage level. The specimen was then retrofitted with carbon fiber polymer and retrofitted specimen is further displaced up to 0.04 drift level which corresponds to permanent damage level.

\section{II.Experimental Study}

Studies have been conducted in Erciyes University Earthquake Laboratory with a $1 / 2$ scaled single-span reinforced concrete frame. The frame is produced with $15 \times 30 \times 225 \mathrm{~cm}$ beams sitting on $25 \times 25 \times 120 \mathrm{~cm}$ columns. The frame is fixed at base with $50 \times 100 \times 310 \mathrm{~cm}$ foundation. Class C30 concrete and the ribbed bar (S420a) have been used in specimens. Seismic detailing conforms TS500 (Turkish Standards) [7] and the Turkish Earthquake Resistant Design Code provisions [8]. Axial load level (Fc x Ac) is set to \%10. Material properties and dimensions of specimens are given below. $(\mathrm{fc}=$ Characteristic compressive cylinder strength of concrete; $A c=$ Gross section area of column or wall end zone)

\section{A. Experimental Specimens}

Defining mechanic properties of the materials is vital to identify certain limit states and to ensure better evaluation of in experimental findings. The physical, chemical and mechanical properties of the materials are summarized below. The mechanical properties of concrete and reinforcement have been determined by laboratory tests in accordance with relevant standards. The aggregates are tested as per standards of TS / EN 706-12620 + A : 2009 [9] , TS / EN 1097-2 [10] and TS / EN 1097-6 [11]. TS EN 1971 [12] conforming cement is used in concrete production namely CEM-I. PÇ 42.5 vcement. Utilized concrete class is $\mathrm{C} 25$ / $30.8 \mathrm{~mm}$ diameter transverse and $14 \mathrm{~mm}$ diameter longitudinal reinforcement is BÇIII-a (S420a) class and tested in accordance with TS-708 (2010) [13].

Frame dimensions are shown in Fig. 1. Frames have been properly cured and before testing a 28 days is waited after manufacture. At the end of 28 says, borehole concrete samples were taken and tested as per TS EN 12504-1 regulations. The corresponding concrete strength is determined as $21 \mathrm{MPa}$.

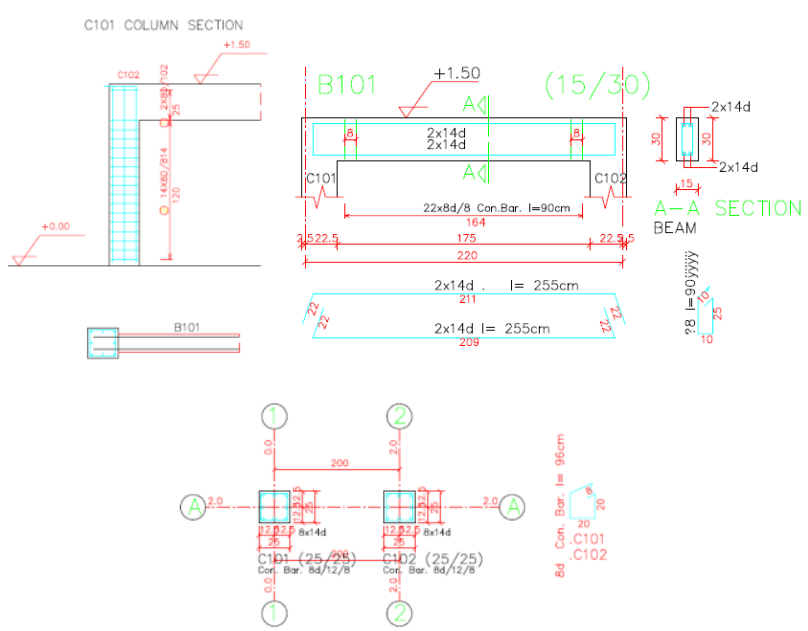

Fig. 1. Specimen Geometric Dimensions

\section{B. Experimental Setup}

Details of the test setup, the instrumentation of the loading system is shown in Fig. 2 and 3. The test specimen is anchored to the laboratory's strong floor through high strength steel bolts. Lateral load is applied by hydraulic actuators at the beam level, and the applied load is measured by a load cell. Column plastic hinge length is assumed to be the half of section depth $(\mathrm{Lp}=0.5 \mathrm{~h})$. Displacements are measured via Linear Variable Differential Transformers (LVDT) that are shown in Fig.2.
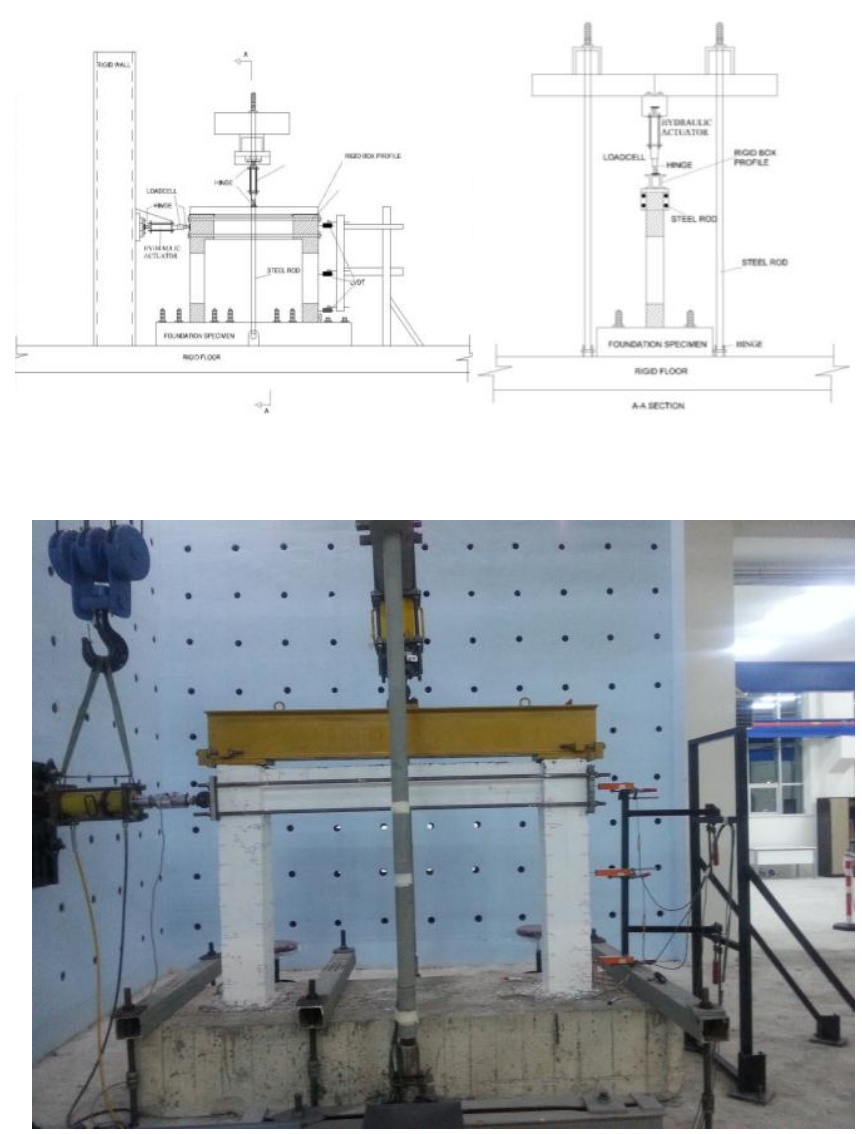

Fig. 2: Test Setup and Instrumentation 


\section{III.Test Results And Discussions}

Under reversal load cycles horizontal displacements are measured. The axial load ratio is constant for all specimens $[0,15 \times \mathrm{fc} \times \mathrm{x}$ Ac]. In which, Ac is gross cross-sectional area of the column and fc is the concrete strength. The applied axial load is $201.98 \mathrm{kN}$ for each column, and kept constant throughout the testing. Forced controlled lateral loading is applied until ultimate load level. Up to ultimate load reverse cycles are applied with an increment of $5 \mathrm{kN}$ in each cycle. Beyond ultimate load displacement controlled loading is applied. In this stage displacement increment is set to $2 \mathrm{~mm}$. Crack growth of the sample at each loading cycle is examined. Since the loading cycles are closely spaced, both progression of the cracks and behaviour of fiber polymer could be thoroughly monitored. Test data is recorded at every 0.25 seconds. The CBFS (Column and Beam Frame System) stands for the bare frame, and "D" stands for the damaged frame in Fig. 3.
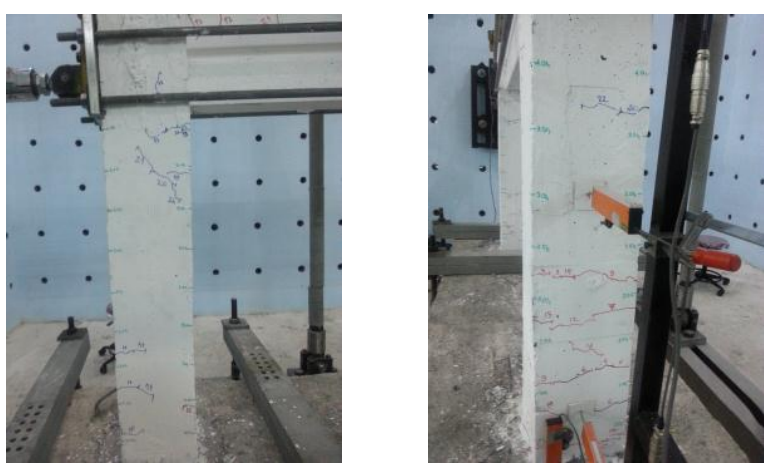

Fig. 3: CBFS-D Specimen

The maximum load applied at this drift is $155.13 \mathrm{kN}$ in pushing and $155.55 \mathrm{kN}$ in pulling cycles. Corresponding displacement values are $0.024 \mathrm{~m}$ and $0.012 \mathrm{~m}$, respectively in Fig. 4. In this case, the sample is damaged and retrofitted with fibre polymer.
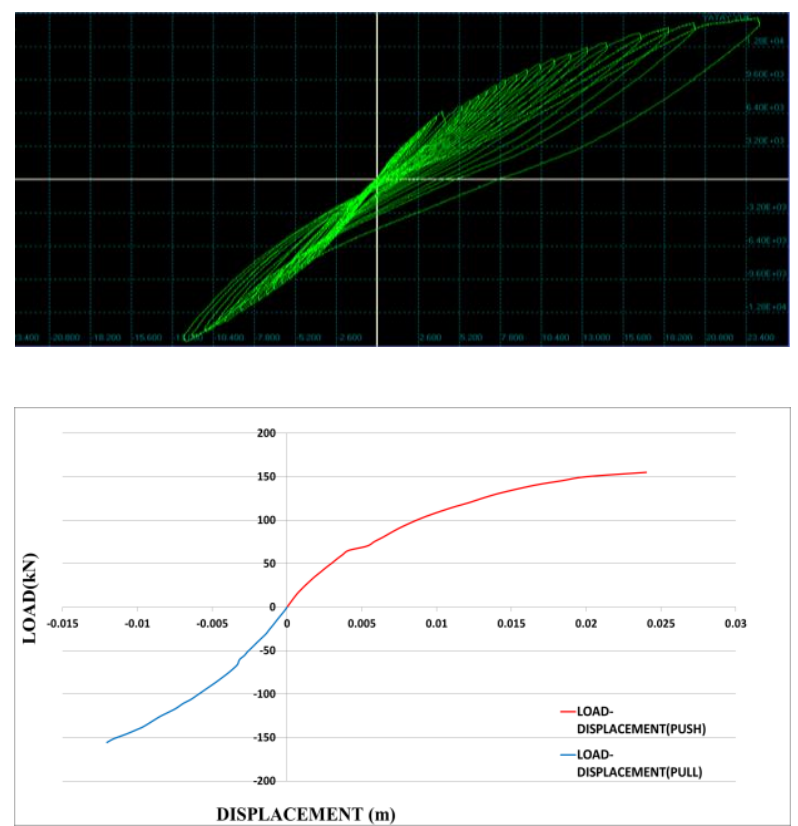

Fig. 4: Load-Displacement Curvature Graphic Damaged frame is displaced until 0.01 drift ratio. The test specimen CBFS -D, is the bare frame which displaced to 0.02 drift ratio in Fig. 5 .

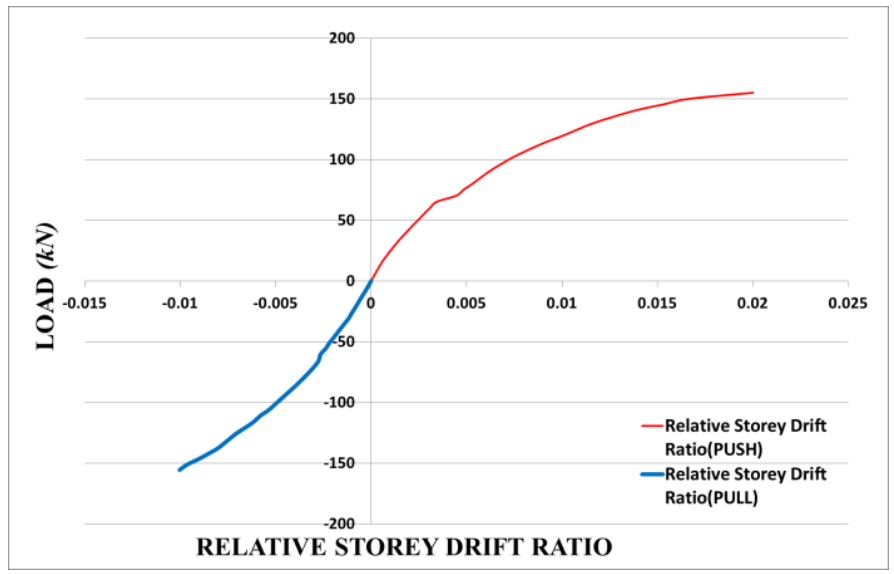

Fig. 5: CBFS-D Specimen Relative Storey Drift Graphic

The test specimen CBFS-DC stands for the carbon fiber retrofitted CBFS-D specimen in Fig. 6.The retrofitting is done according to Turkısh Earthquake Code regulations. This specimen is then displaced to 0.04 drift (Extensive Damage Region to Collapsing Region) level.
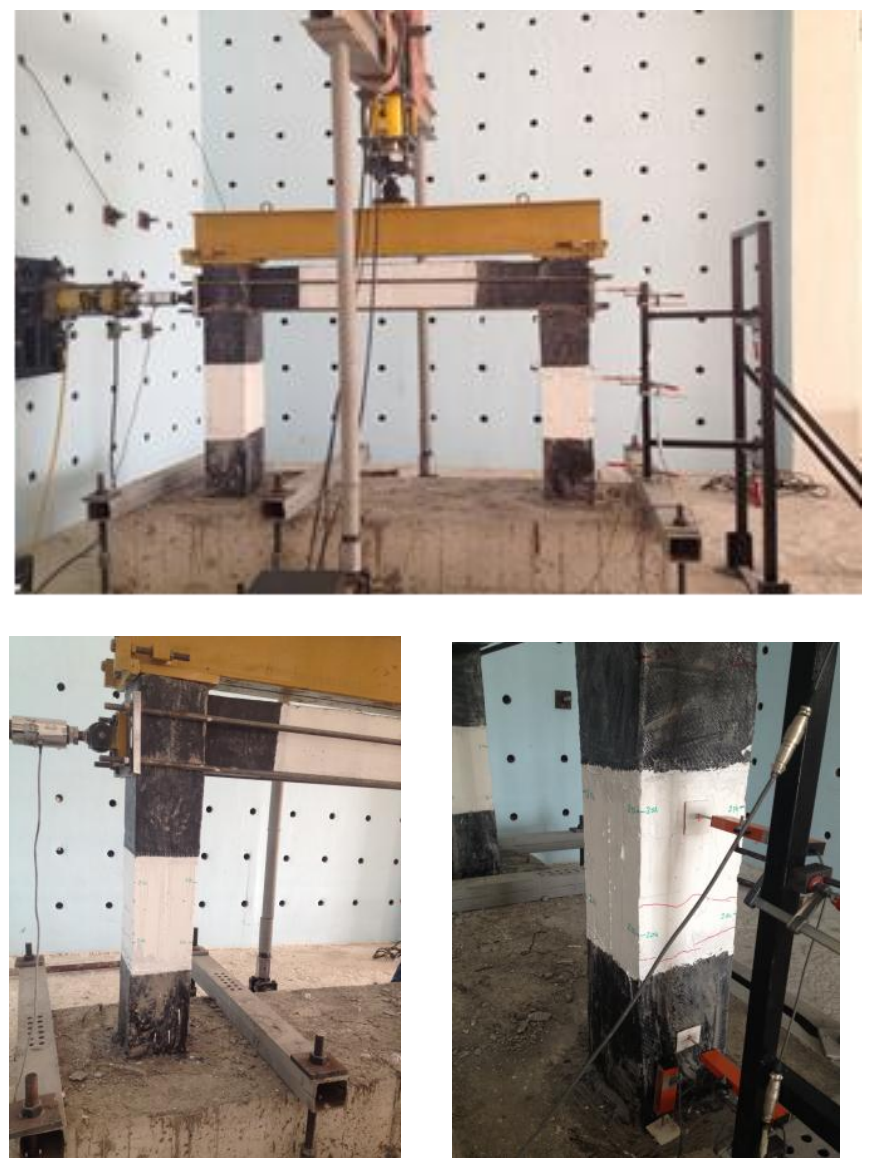

Fig. 6: CBFS-DC Specimen 
The same load testing protocol was applied as in the other specimens. The largest applied lateral force is $187.93 \mathrm{kN}$ for pushing and $192.90 \mathrm{kN}$ for pulling in Fig. 7. The corresponding lateral displacement is $0.045 \mathrm{~m}$ for pushing and $0.041 \mathrm{~m}$ for pulling.
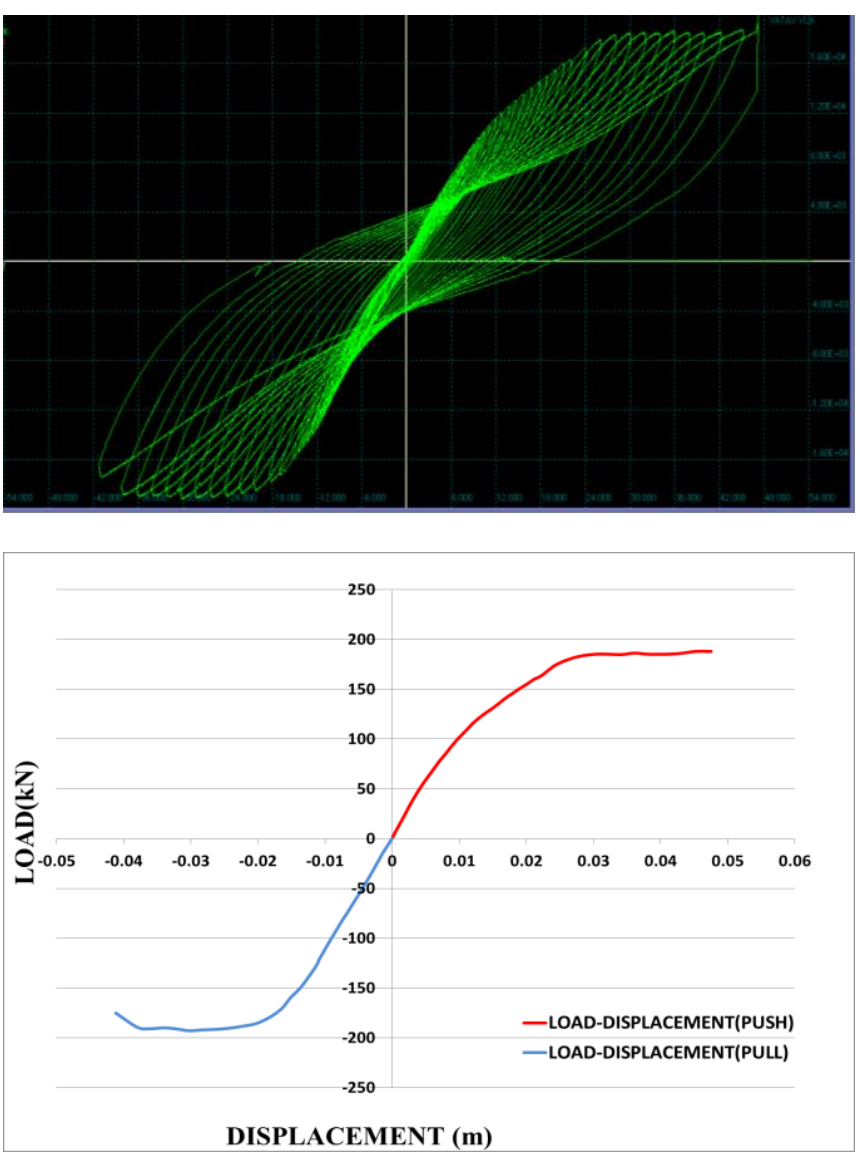

Fig. 7 Load-Displacement Curvature Graphic

The calculated relative storey drift's ratio is 0.039 at this level which corresponds to extended damage limit in Fig. 8.

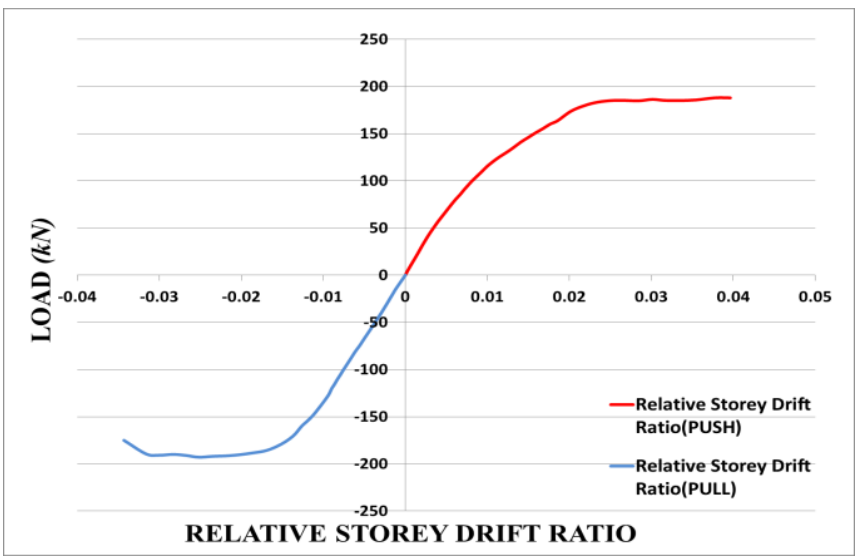

Fig. 8: CBFS-DC Specimen Relative Storey Drift Graphic
The lateral load applied to the 5th cycle of the CBFS-D specimen was $20.05 \mathrm{kN}$, and the displacement of the lateral started to crack at the level of $0.929 \mathrm{~mm}$. Relative storey drift was monitored of the first crack is at the level of 0.0008

The lateral load applied to the pushing in the 7th cycle of the CBFS-DC specimen is $40.10 \mathrm{kN}$, and the displacement of the horizontal has started to occur at the level of $3.525 \mathrm{~mm}$.

Although any cracks were monitored around $20.39 \mathrm{kN}$ of the undamaged specimen, this level increased to $40.10 \mathrm{kN}$ after strengthening with the fibre polymer, lateral displacements were observed at $3.5 \mathrm{~mm}$, with further increase in strength.

Relative storey drift of the first crack is level of 0.002. When the system goes out of the elastic region, there is a decrease in stiffness.

The displacement level of corresponding to ultimate load in CBFS-D specimen was $24,78 \mathrm{~mm}$ which corresponds to 0,016 drift ratio in pushing cycle. This is the upper limit of the minimum damage region. In the pulling cycle displacement level of corresponding to ultimate load is $12,019 \mathrm{~mm}$ which corresponds to 0,008 drift ratio. Crack growts are pictured thoroughly in MSc. thesis of Author. [14].
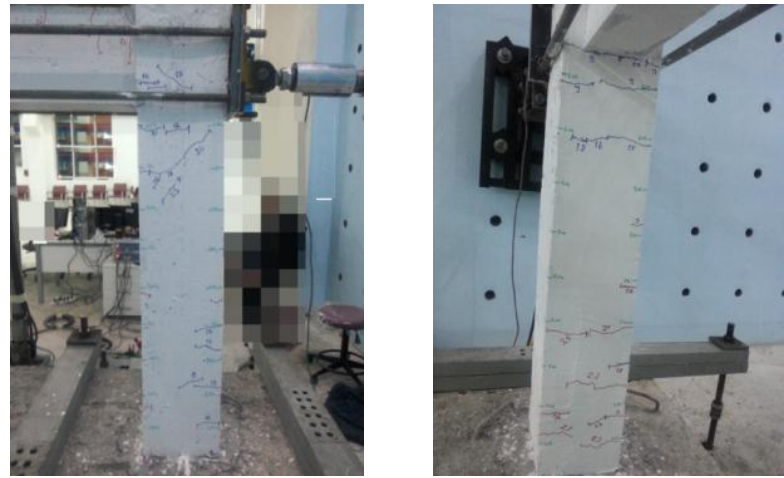

Fig. 9: CBFS-D Specimen's Crack Development

The displacement level of corresponding to ultimate load in CBFS-DC specimen was $42,28 \mathrm{~mm}$ which corresponds to $0,03 \mathrm{drift}$ ratio in pushing cycle. This is the upper limit of the extensive damage region. In the pulling cycle displacement level of corresponding to ultimate load is $30,23 \mathrm{~mm}$ which corresponds to 0,02 drift ratio. 

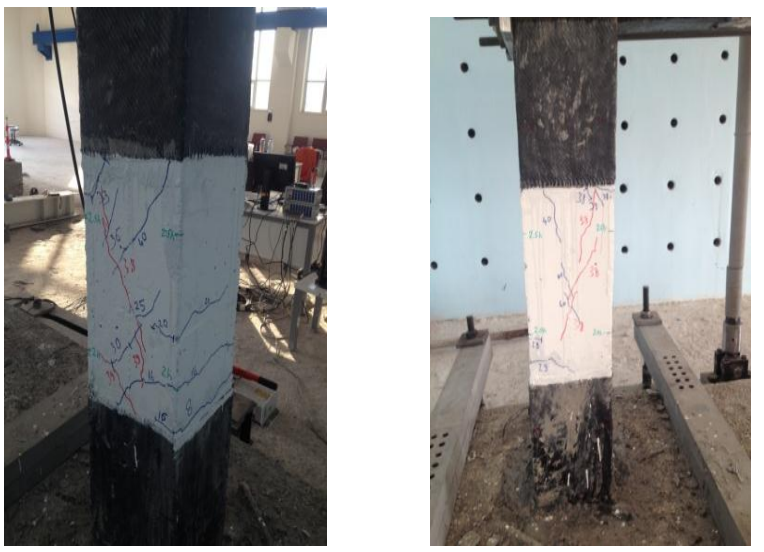

Fig. 10: CBFS-DC Specimen's Crack Development

\section{IV.Conclusions}

In the study all of the specimens were tested under the effect of pushing and pulling forces applied laterality in one direction with constant axial force. The axial force ratio is kept constant with a tolerance of $\pm 10 \%$. For each push and pull cycle $5 \mathrm{kN}$ lateral force is applied to the specimen. In addition, lateral force is increased $5 \mathrm{kN}$ end of each cycle.

As a result, while ultimate moment resistant capacity was reduced, reinforced concrete columns were found to be poured in shell concretes, in contrast rupture and scrape is not observed in the transverse reinforcement elements.

I. In this case, relative storey drift between 0 to 0.02 frame is is damaged. After that retrofitted with fibre polymer. As a result, which is the minimum damage level was strengthen with the fibrous polymer. 25 $\mathrm{kN}$ force in the specimen at 5th loop, the first crack is observed from the top foundation at a height about $125 \mathrm{~mm}$.

II. In the loop behaviour of the fibrous polymer is under cyclic loading, that lateral force was increased the load level of the reinforced concrete frame system by $17 \%$ and reduced the ductility of the specimens by $46 \%$ in the case of damaged fibre polymer reinforced specimen.

III. As a consequence of this behaviour, the fibrous polymer improve stiffness of structural members, can be interpreted as limiting the capability of the members to move laterally and ductility. In the case of columns, there is a slight increase in strength due to the fibrous polymer used according to the axial load level and strength to flexural does not increase.

IV. CBFS-DC specimen is confined with the fibrous polymer behaviour; the strength did not fall immediately after the maximum peak point, even close to the fixed, allowing more displacement than the unconfined model. This shows us that the fiber polymer contributes to the ductility and energy consumption of the system by effecting the concrete confinement. However, it has been found that carbon fiber polymers do not contribute to flexural strength.

V. As a result, it has been seen that carbon fiber polymers contribute to the repair of building materials. In addition, structure member at minimum damage region to reinforced concrete system due to high strength, and can be retrofit to its old capacity.

\section{Acknowledgements}

This study has been supported by Erciyes University's Scientific Research Projects Directorate with number of ID 4671. Their support is gratefully acknowledged. The authors also wish to express their appreciation to the staff of Erciyes University's Structures Laboratory for their help and support.

\section{References}

[1].O. Anil, 2006. Improving shear capacity of RC T-beams using CFRP composites subjected to cyclic load, Cement and Concrete Composites Volume 28, Issue 7 :638-649

[2].C. Yalcin., O. Kaya.,M. Sinangil, (2008). "Seismic retrofitting of R/C columns having plain rebars using CFRP sheets for improved strength and ductility." Construction and Building Materials 22: 295307

[3]. Singh, V., Bansal, P.P., Kumar, M., Kaushik, S.K., 2014, "Experimental Studies on Strength and Ductility of CFRP Jacketed Reinforced Concrete Beam-Column Joints", Construction and Building Materials, Vol:55, 194-201..

[4].Garcia, R. , Iman Hajira Souliha, Pilakoutas K. , 2010, “ Seismic Behaviour Of Deficient RC Frames Strengthened With CFRP Composites" Engineering Structures 32, 3075-3085

[5].Ritchie, P., Thomas, D., Lu, W. L., and Connelly, G., 1991, "External reinforcement Of Concrete Beams Using Fiber Reinforced Plastics.”ACI Struct. J.,88, 490-500.

[6].Geng, Z.J., Chajes, M.J., Chou, T.W., Pan, D.Y., 1998,"The Retrofitting of Reinforced Concrete Column-to-Beam Connections", Composites Science and Technology 58, 1297-1305.

[7]. TS500/2000. Requirements for Design and Construction of Reinforced Concrete Structures. Turkish Standards Institution (TSI)

[8].Turkish Earthquake Resistant Design Code. Ministry of Public Works and Settlement. Turkey: Ankara; 2007

[9].TS/EN 706-12620+A, 2009. Concrete Aggregate. Turk Standards Institute, Ankara, TURKEY

[10].TS/EN 1097-2/A1, 2010. Tests for mechanical and physical properties of aggregates - Part 2: Methods for the determination of resistance to fragmentation. Turkish Standards Institution (TSI)

[11].TS/EN 1097-6, 2013. Tests for mechanical and physical properties of aggregates - Part 6: Determination of particle density and water absorption Turkish Standards Institution (TSI)

[12].TS/EN 197-1, 2012. This standard describes the method of measuring the pozzolanicity of pozzolanic cements. Turkish Standards Institution (TSI)

[13].TS 708, 2010. Steel for the reinforcement of concrete - Reinforcing Steel. Turkish Standards Institution (TSI)

[14].Sulev E., (2016). "Analytical and Numerical Investigation of Reinforced Concrete Frame Joints Confined with Carbon Fiber Reinforced Polymer." MSc. thesis, Natural And Applied Sciences Institute of Erciyes University, Kayseri, Turkey.

Please attached documentary conference paper written by Ertan SULEV and Fatih "ALTUN IMPROVING EARTHQUAKE PERFORMANCE OF REINFORCED CONCRETE FRAMES WITH CFRP"

Kindly Regards 